\title{
Simplified flow cytometric immunophenotyping panel for multiple myeloma, CD56/CD19/CD138(CD38)/CD45, to differentiate neoplastic myeloma cells from reactive plasma cells
}

\author{
Tae-Dong Jeong ${ }^{1}$, Chan-Jeoung Park ${ }^{1}$, Hyoeun Shim ${ }^{2}$, Seongsoo Jang ${ }^{1}$, Hyun-Sook Chi ${ }^{1}$, \\ Dok Hyun Yoon ${ }^{3}$, Dae-Young Kim ${ }^{3}$, Jung-Hee Lee ${ }^{3}$, Je-Hwan Lee ${ }^{3}$, Cheolwon Suh ${ }^{3}$, Kyoo Hyung Lee ${ }^{3}$ \\ ${ }^{1}$ Department of Laboratory Medicine, University of Ulsan College of Medicine and Asan Medical Center, Seoul, ${ }^{2}$ Department of \\ Laboratory Medicine, Ajou University School of Medicine, Suwon, ${ }^{3}$ Department of Internal Medicine, University of Ulsan College \\ of Medicine and Asan Medical Center, Seoul, Korea
}

p-ISSN 1738-7949 / e-ISSN 2092-9129

http://dx.doi.org/10.5045/kjh.2012.47.4.260

Korean J Hematol 2012;47:260-6.

Received on July 16, 2012

Revised on September 27, 2012

Accepted on November 6, 2012

\section{Correspondence to}

Chan-Jeoung Park, M.D., Ph.D. Department of Laboratory Medicine, University of Ulsan College of Medicine and Asan Medical Center, 88, Olympic-ro 43-gil, Songpa-gu, Seoul 138-736, Korea Tel: $+82-2-3010-4508$

Fax: $+82-2-478-0884$

E-mail: cjpark@amc.seoul.kr

(C) 2012 Korean Society of Hematology

\section{Background}

Flow cytometric immunophenotyping has been used to identify neoplastic plasma cell populations in patients with multiple myeloma (MM). Previous reports have described the use of several antigens, including CD38, CD138, CD56, CD117, CD52, CD19 and CD45, to distinguish distinct populations of plasma cells. The aim of this study was to evaluate a simplified immunophenotyping panel for MM analysis.

\section{Methods}

A total of 70 patients were enrolled in the study, 62 of which were newly diagnosed with MM (untreated), whereas the remaining 8 were undergoing bone marrow assessment as part of follow-up after treatment (treated). Treated cases included 3 patients with relapse and 5 patients with persistence of MM. Multiparametric flow cytometric immunophenotyping was performed using monoclonal antibodies against CD56, CD19, CD138 (CD38), and CD45.

Results

In differential counts, plasma cells in bone marrow (BM) accounted for 3.6-93.2\% of the total nucleated cell count. The positive expression rates of CD56, CD19, CD138, and CD45 in neoplastic myeloma cells were $83.9 \%, 0 \%, 98.4 \%$, and $37.1 \%$, respectively, among the 62 untreated cases, and $75.0 \%, 0 \%, 87.5 \%$, and $37.5 \%$, respectively, among the 8 treated cases. CD19 expression of neoplastic plasma cells was negative in both untreated and treated cases.

\section{Conclusion}

The simplified immunophenotyping panel, CD56/CD19/CD138(CD38)/CD45, is useful for distinguishing neoplastic myeloma cells from reactive plasma cells in clinical practice. In addition, CD19 represents the most valuable antigen for identifying neoplastic myeloma cells in patients with MM.

Key Words Multiple myeloma, Flow cytometry, Immunophenotyping, Neoplastic plasma cells, CD19 negativity

\section{INTRODUCTION}

Multiple myeloma (MM) is a clonal B-cell neoplasm resulting in the accumulation of neoplastic plasma cells in the bone marrow (BM) [1]. In most cases of MM, an abnormal paraprotein known as monoclonal protein is produced. A
MM diagnosis is confirmed by the presence of neoplastic plasma cells in the BM, as well as detection of monoclonal protein in the blood or urine [2]. Although most of the plasma cells in patients with $\mathrm{MM}$ are neoplastic myeloma cells, a small percentage of normal or reactive plasma cells remain, which are responsible for maintaining normal immune function [3].

\footnotetext{
This is an Open Access article distributed under the terms of the Creative Commons Attribution Non-Commercial License (http://creativecommons.org/licenses/by-nc/3.0)
} which permits unrestricted non-commercial use, distribution, and reproduction in any medium, provided the original work is properly cited. 
Flow cytometry (FCM)-based immunophenotyping has become a mandatory diagnostic tool to discriminate neoplastic plasma cells from reactive plasma cells in clinical laboratories. A number of previous studies have demonstrated that various antigens are expressed on plasma cells such as CD19, CD20, CD27, CD33, CD38, CD45, CD56, CD117, and CD138 [3-9], with neoplastic plasma cells and reactive plasma cells each displaying distinct immunophenotypic profiles. Reactive plasma cells are characterized by low forward/side scatter (FSC/SCC) and high CD38 expression together with a CD19+/CD56- phenotype $[6,10,11]$. In contrast, neoplastic plasma cells are CD19-/CD56+ or -, with high FSC/SSC and relatively low CD38 expression. [6, 10, 11]. The European Myeloma Network (EMN) has recommended the most useful antigens for the detection of aberrant plasma cells in MM [12]. These recommendations can be classified into 3 categories according to the requirements for diagnosis and monitoring: CD19 and CD56 are "essential"; CD117, CD20, CD28, and CD27 are "recommended"; and CD81 and CD200 are "suggested" [12].

Because there is no established standard FCM immunophenotyping panel for $\mathrm{MM}$, we aimed to evaluate a simplified panel, CD56/CD19/CD138(CD38)/CD45, for analysis of this disease.

\section{MATERIALS AND METHODS}

\section{Study population}

A total of 70 patients were enrolled in this study from April 2010 to July 2011, of which, 62 were newly diagnosed with MM (untreated) and the remaining 8 were undergoing $\mathrm{BM}$ analysis as a part of follow-up to treatment for MM (treated). MM was diagnosed using the 2008 World Health Organization classification [13]. This study was approved by the institutional review board of the Asan Medical Center, and all patients provided their informed consent before collection of their bone marrow specimens.

\section{FCM immunophenotyping}

Multiparametric FCM immunophenotyping was performed using monoclonal antibodies against CD56, CD19, CD138 (CD38), and CD45. Briefly, BM aspirate specimens collected in tubes with ethylenediaminetetraacetic acid as the anticoagulant were washed in phosphate-buffered saline (PBS) and resuspended in PBS with $1.0 \%$ bovine serum albumin
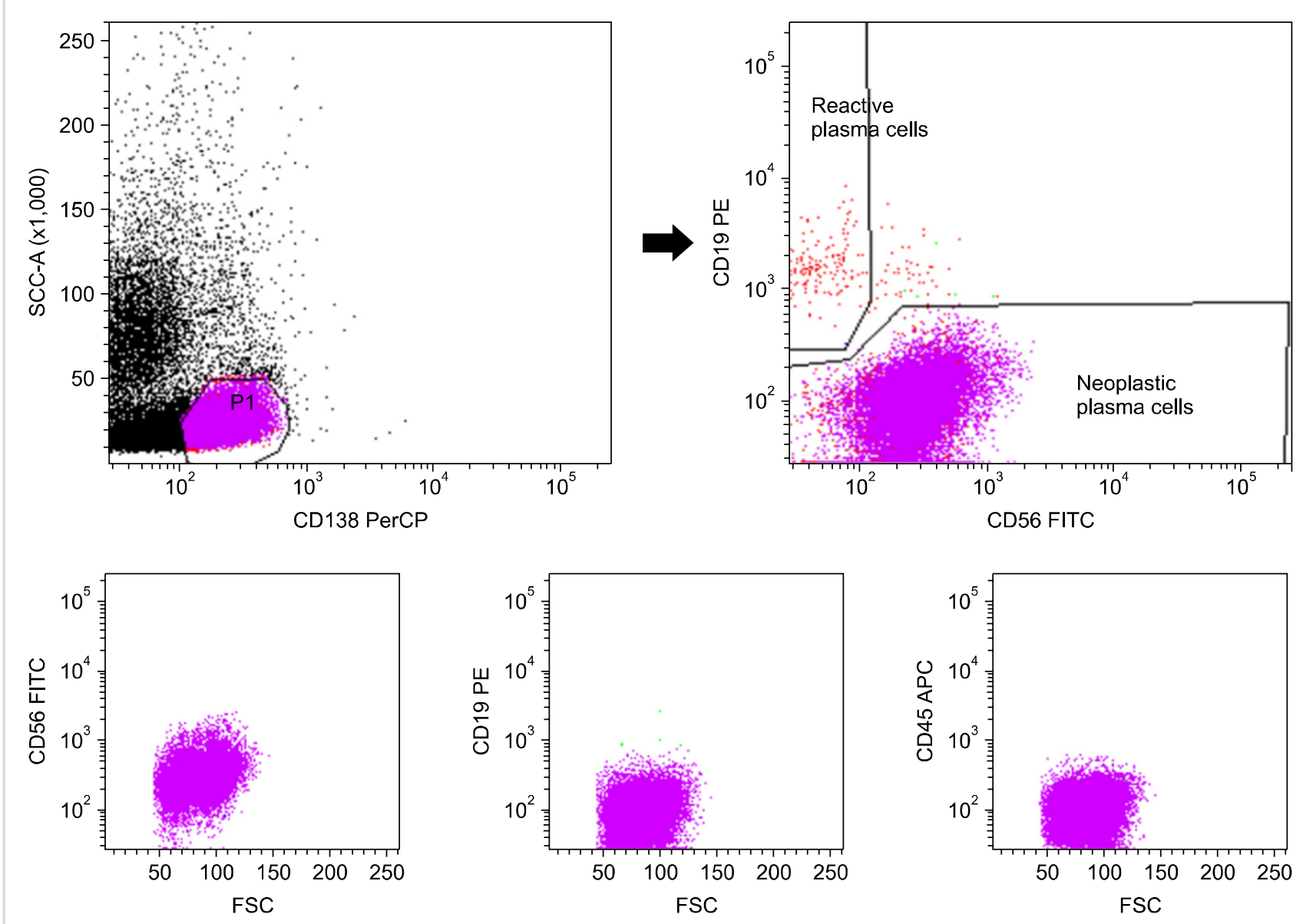

Fig. 1. Typical laboratory protocol for distinguishing neoplastic plasma cells (CD56+or-/CD19-/CD138+/CD45-) from reactive plasma cells (CD56-/CD19+/CD138+/CD45+) in patients with multiple myeloma. Plasma cells were gated with CD138+ and low side scatter and were distinguished as neoplastic plasma cells (CD56+/CD19-/CD138+/CD45-) and reactive plasma cells (CD56-/CD19+/CD138+/CD45+). 


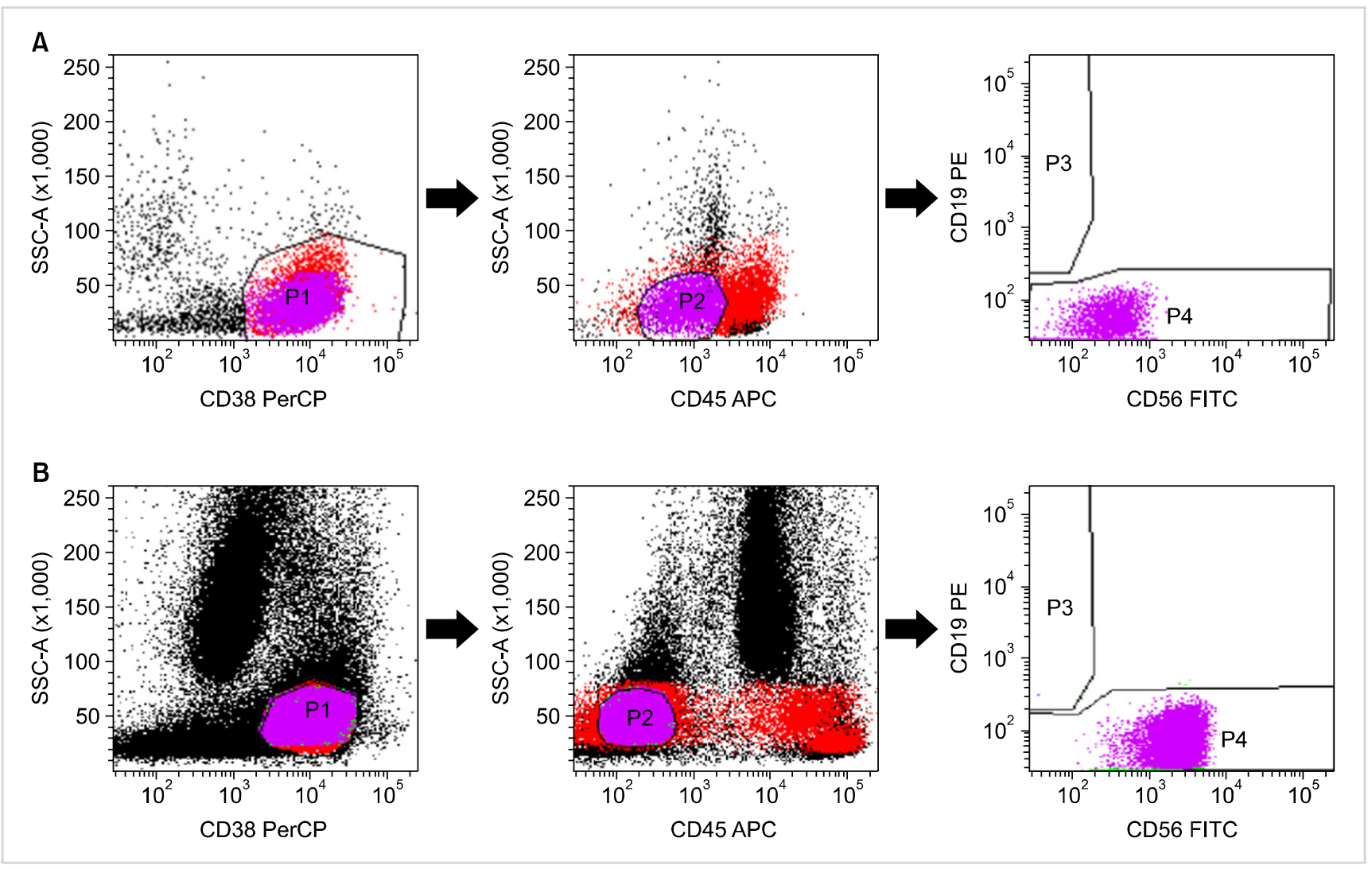

Fig. 2. Flow cytometric immunophenotyping of 2 cases (A and B) with CD138-negative neoplastic plasma cells. Plasma cells were gated with CD38+ and low side scatter, followed by selection of CD45-dim (A) and CD45-negative (B) cells. In the both cases (A and B), neoplastic plasma cells showed CD19- and CD56+ expression (A, dim and B, intermediate).

to a final adjusted white blood cell count of $1-2 \times 10^{6} / \mathrm{mL}$. Next, $100 \mu \mathrm{L}$ of washed BM aspirates were briefly vortexed for $3 \mathrm{~s}$ before incubation with $10 \mu \mathrm{L}$ of each of the monoclonal antibodies for $25 \mathrm{~min}$ at room temperature in the dark. Five monoclonal antibodies were used for FCM immunophenotyping: fluorescein isothiocyanate (FITC)-conjugated anti-CD56; phycoerythrin (PE)-conjugated anti-CD19; peridinin chlorophyll protein (PerCP)-conjugated anti-CD138; PerCP-conjugated anti-CD38; and allophycocyanin (APC)conjugated anti-CD45. Lysis solution was added to the tube, vortexed immediately for $10 \mathrm{~min}$, and then incubated for $10 \mathrm{~min}$ at room temperature in the dark. After washing with PBS, cells were fixed by the addition of $500 \mu \mathrm{L}$ of $1 \%$ PBS-formaldehyde. The acquisition of 50,000 nucleated cells and subsequent analyses were performed using a FACSCanto II flow cytometer (BD Bioscience, San Jose, CA, USA).

The plasma cells were initially identified using CD138 and side scatter, following which, CD138+ gated cells were analyzed for CD56, CD19, and CD45 (Fig. 1). In cases of CD138- specimens, the BM aspirate was restained with a CD56/CD19/CD38/CD45 panel. In this case, plasma cells were gated using CD38 and side scatter, and CD38+ cells with low side scatter were re-gated for negative or intermediate CD45 expression (Fig. 2).

\section{Definition of neoplastic plasma cells}

In cases of simultaneous detection of both neoplastic and reactive plasma cells by gating using CD138, we defined neoplastic plasma cells as CD138+/CD56-or+/CD19-/CD45variable (Fig. 1). The representative reactive plasma cells were defined as CD138+/CD56-/CD19+/CD45+.

If the neoplastic plasma cells were negative for CD138, samples were reanalyzed, and neoplastic plasma cells were defined as CD38+/CD56+or-/CD19+/CD45variable (Fig. 2).

\section{Serum monoclonal component (M-component)}

Visual detection of a monoclonal band following serum protein electrophoresis was used to confirm the presence of monoclonal protein. The percentage of monoclonal protein was quantified by using a densitometer, and the absolute concentrations of monoclonal protein $(\mathrm{g} / \mathrm{L})$ were calculated from total serum protein concentrations.

\section{Statistical analysis}

Continuous values were reported as mean \pm SD and were compared using the Mann-Whitney U test. The categorical data was analyzed using Fisher's exact test. A correlation analysis was performed to identify the strength of association between the monoclonal component and the neoplastic plasma cell fraction or the proportion of BM nucleated cells as determined using FCM. All statistical analyses were per- 
formed using SPSS version 18.0 (SPSS, Inc., Chicago, IL, USA), with $P<0.05$ considered statistically significant.

\section{RESULTS}

The study included 70 patients ( 37 male and 33 female). Patient demographics are summarized in Table 1. Of the 70 patients, 8 were undergoing follow-up after diagnosis and treatment of MM. The chemotherapy regimens included vincristine, doxorubicin, and dexamethasone; melphalan and prednisone and/or thalidomide; or thalidomide and dexamethasone. These follow-up cases included 3 patients with relapse of $\mathrm{MM}$ and 5 with persistence of MM. No significant difference was noted in the clinical variables between the untreated and treated patients.

In 68 of 70 cases, plasma cells could be sufficiently identified through initial CD138 gating. The overall positive expression rates of CD56, CD19, CD138, and CD45 in neoplastic myeloma cells, were $83.9 \%$ (52/62), 0\% (0/62), 98.4\% (61/62), and $37.1 \%(23 / 62)$, respectively, among 62 untreated cases, and $75.0 \%(6 / 8), 0 \%(0 / 8), 87.5 \%(7 / 8)$, and $37.5 \%(3 / 8)$, respectively, among the 8 treated cases (Table 2). Two of the 70 cases were negative for CD138 expression following initial CD138 gating and were subsequently restained and gated using CD38. The clinical and laboratory characteristics of these 2 cases are summarized in Table 3, and their FCM immunophenotyping profiles are shown in Fig. 2.

Table 1. Patient demographics.

\begin{tabular}{|c|c|c|c|}
\hline Characteristic & Diagnosed patients (untreated) $(\mathrm{N}=62)$ & Follow-up patients (treated) $(\mathrm{N}=8)$ & $P^{\mathrm{a})}$ \\
\hline Median age (range) & $67(27-89)$ & $65(54-76)$ & NS \\
\hline Female $(\%)$ & $29(46.8)$ & $4(50.0)$ & NS \\
\hline Plasma cell $^{\mathrm{b})}(\%)$ & $32.9 \pm 24.1$ & $40.9 \pm 27.3$ & NS \\
\hline \multicolumn{4}{|l|}{ Ig type } \\
\hline $\lg A$ & 22 & 4 & \\
\hline IgG & 24 & 1 & \\
\hline $\lg D$ & 2 & 1 & \\
\hline Light chain only & 11 & 2 & \\
\hline $\lg A$ and $\lg G$ & 1 & - & \\
\hline Not available & 2 & - & \\
\hline $\mathrm{Hb}(\mathrm{g} / \mathrm{dL})$ & $10.2 \pm 2.3$ & $10.2 \pm 3.3$ & NS \\
\hline Albumin (g/dL) & $3.1 \pm 0.7$ & $3.4 \pm 0.5$ & NS \\
\hline Calcium (mg/dL) & $8.8 \pm 0.9$ & $8.6 \pm 0.6$ & NS \\
\hline LD (IU/L) & $220.5 \pm 193.3$ & $189.9 \pm 46.8$ & NS \\
\hline $\mathrm{CRP}(\mathrm{mg} / \mathrm{dL})$ & $2.0 \pm 3.7$ & $2.7 \pm 4.4$ & NS \\
\hline$\beta$ 2-Microglobulin $(\mu \mathrm{g} / \mathrm{mL})$ & $6.6 \pm 8.7$ & $10.1 \pm 8.3$ & NS \\
\hline \multicolumn{4}{|l|}{ ISS staging } \\
\hline I & 14 & 0 & \\
\hline II & 28 & 1 & \\
\hline III & 17 & 2 & \\
\hline Not available & 3 & 5 & \\
\hline
\end{tabular}

Table 2. Comparison of overall positive expression rates for CD56, CD19, CD138, and CD45 in neoplastic myeloma cells between the untreated and treated patients.

\begin{tabular}{|c|c|c|c|c|}
\hline Antigen & Expression & $\begin{array}{c}\text { Untreated patients }(\mathrm{N}=62) \\
\mathrm{N}(\%)\end{array}$ & $\begin{array}{l}\text { Treated patients }(\mathrm{N}=8) \\
\mathrm{N}(\%)\end{array}$ & $P$ \\
\hline \multirow{2}{*}{ CD138 } & Pos & $61(98.4)$ & 7 (87.5) & 0.217 \\
\hline & Neg & $1(1.6)$ & $1(12.5)$ & \\
\hline \multirow[t]{2}{*}{ CD56 } & Pos & 52 (83.9) & $6(75.0)$ & 0.618 \\
\hline & Neg & $10(16.1)$ & $2(25.0)$ & \\
\hline \multirow[t]{2}{*}{ CD19 } & Pos & $0(0.0)$ & $0(0.0)$ & NA \\
\hline & Neg & $62(100.0)$ & $8(100.0)$ & \\
\hline \multirow[t]{4}{*}{ CD45 } & Dim & $4(6.5)$ & $0(0.0)$ & 1.000 \\
\hline & Intermediate & $7(11.3)$ & $3(37.5)$ & \\
\hline & Bright & 12 (19.4) & $0(0.0)$ & \\
\hline & Neg & 39 (62.9) & $5(62.5)$ & \\
\hline
\end{tabular}

Abbreviations: NA, not available; Neg, negative; Pos, positive. 
The immunophenotype of neoplastic plasma cells was not different between the untreated and treated patients. Neoplastic plasma cell CD19 expression was completely negative in both groups of patients. According to FCM analysis, the median percentage of neoplastic plasma cells among the total plasma cells was $95.4 \%$ (range, 13.3-99.6\%) and that of reactive plasma cells was $4.6 \%$ (range, $0.4-86.7 \%$ ). No difference was noted in the proportions of neoplastic plasma cells between the untreated and treated patients (Table 4).

In the correlation analysis between the neoplastic plasma cell fraction, detected using FCM, and the M-component, calculated from serum protein electrophoresis, a weak positive correlation was noted $(\mathrm{r}=0.15)$; however, this was not statistically significant $(P=0.245)$. In contrast, the neoplastic plasma cell proportion in $\mathrm{BM}$ aspirates [(fraction of neoplastic

Table 3. Clinical and laboratory characteristics of 2 cases with CD138-negative neoplastic plasma cells according to FCM immunophenotyping.

\begin{tabular}{lcc}
\multicolumn{1}{c}{ Variables } & Case A & Case B \\
\hline Time of study & Diagnosis & Relapse \\
Calcium $(\mathrm{mg} / \mathrm{dL})$ & 8.5 & 8.3 \\
Creatinine $(\mathrm{mg} / \mathrm{dL})$ & 1.1 & 1.5 \\
Hemoglobin $(\mathrm{g} / \mathrm{dL})$ & 6.2 & 8.7 \\
Lytic bone lesion & None & Not tested \\
Serum EP, M-peak $(\mathrm{g} / \mathrm{dL})$ & 0.6 & 0.3 \\
Serum IFE & Free $\kappa$ type & IgA $\lambda$ type \\
BM plasma cells $(\%)$ & 82.4 & 45.2
\end{tabular}

Abbreviations: EP, electrophoresis; IFE, immunofixation electrophoresis. plasma cells according to $\mathrm{FCM}) \times($ percentage of plasma cells among the total nucleated cells in BM aspirates according to differential cell count)] showed a statistically significant weak positive correlation with the M-component ( $\mathrm{r}=0.26$, $P=0.045$ ) (Fig. 3).

\section{DISCUSSION}

Neoplastic plasma cells have been previously identified according to their CD38++/CD45- or dim expression [3]. However, CD38 is a non-specific marker for plasma cells because it has a wide distribution and is displayed on the surface of both hematopoietic and nonhematopoietic cells, with most reports on CD38 focusing on its expression on B- and T-lymphocytes [14]. In addition, CD45+ myeloma cells have been reported [15]. To resolve these potential issues, we used CD138 for the initial identification of plasma cells. Because plasma cells are the only cells in the BM

Table 4. Comparison of the proportion of neoplastic plasma cells between the untreated and treated patients.

\begin{tabular}{lccc}
\hline $\begin{array}{c}\text { Neoplastic } \\
\text { plasma cells }(\%)\end{array}$ & $\begin{array}{c}\text { Untreated patients } \\
(\mathrm{N}=62)\end{array}$ & $\begin{array}{c}\text { Treated patients } \\
(\mathrm{N}=8)\end{array}$ & $P$ \\
\hline Median & 94.3 & 96.5 & \\
Mean & 81.9 & 86.4 & 0.252 \\
SD & 23.5 & 29.6 & \\
Maximum & 99.6 & 99.2 & \\
Minimum & 24.5 & 13.3 & \\
\hline
\end{tabular}

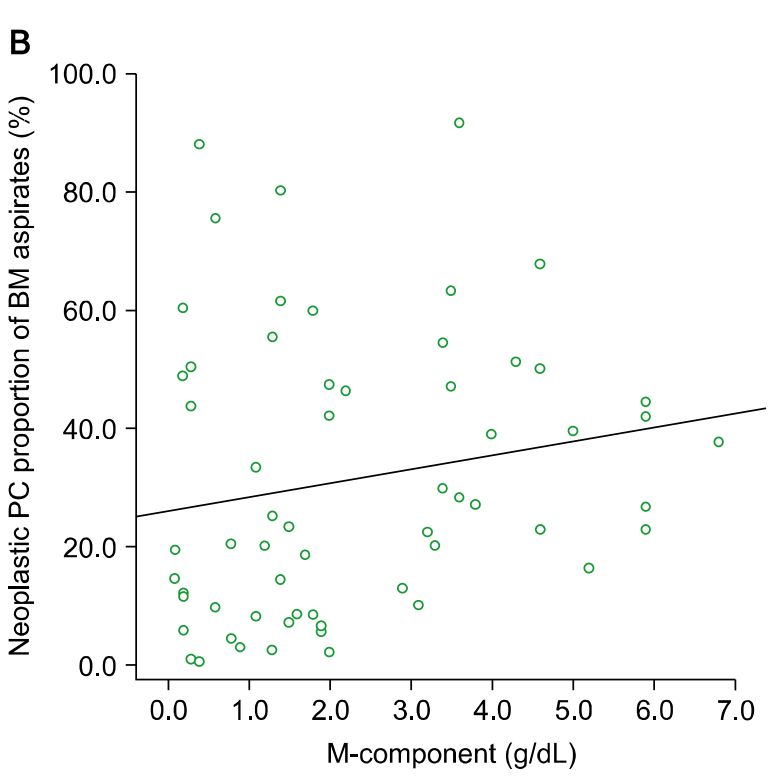

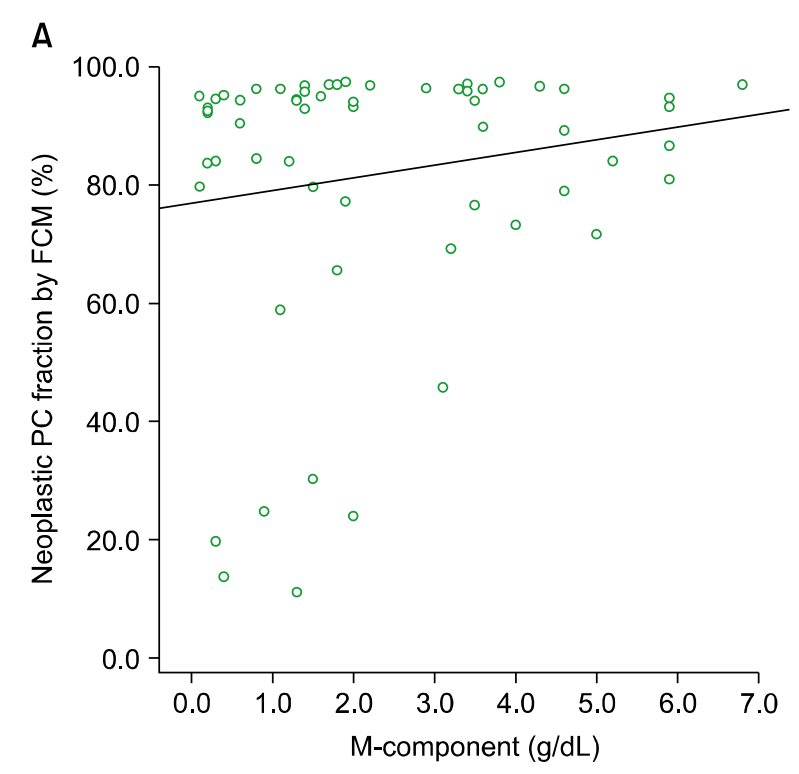

Fig. 3. Comparison of the monoclonal immunoglobulin component (M-component) and the tumor burden of neoplastic plasma cells (PCs) in bone marrow (BM) aspirates according to flow cytometry (FCM). (A) A weak positive correlation ( $r=0.15)$ was noted between the fraction of neoplastic PCs according to FCM and the $M$-component, but this was not statistical significant $(P=0.245)$. (B) The proportion of neoplastic PCs in BM aspirates, i.e., fraction of neoplastic PCs according to FCM $\times$ percentage of PCs among the total number of nucleated cells in the BM aspirates according to differential cell count, showed a statistically significant positive correlation with the $M$-component $(r=0.26, P=0.045)$. 
that express CD138, this marker can be used to identify and isolate this population for further FCM analysis [16]. CD138 gating identifies a much more homogeneous population of myeloma cells than CD38 gating [15]. Because the immunophenotype of myeloma cells is not significantly different between untreated and treated patients [15], the CD138 antigen could be used for FCM analysis in both patients groups. However, a small component of plasma cells does not express CD138 [16]. In our study, 68 of 70 cases (97.1\%) showed CD138+ neoplastic plasma cells, with only 2 cases $(2 / 70,2.9 \%)$ with CD138- neoplastic plasma cells. However, this later group showed CD38+ neoplastic plasma cells, and therefore, in these cases, CD38 was used for selection. No difference was noted in the immunophenotypic profile (CD56+/CD19-/CD45+) between CD38+ cells and cells gated using the CD138 marker. The EMN has presented data demonstrating that CD138 alone is not an adequate marker for the primary gating of plasma cells. The simultaneous detection of both CD138 and CD38 is recommended for increased precision and reduction in interobserver variation [12]. Although we failed to detect a sub-population of neoplastic plasma cells with dim-to-negative CD138 expression by using CD138 gating alone, separate analysis of CD138- cells on the basis of CD38 expression could be used to detect myeloma cells with dim-to-negative CD138 expression. Thus, initial gating using CD138 followed by subsequent selection using CD38 only for samples with dim-tonegative CD138 expression, may represent a simplified workflow for MM characterization in clinical laboratories. However, because the immunophenotype of natural killer (NK) cells can often be identified as CD38+/CD56+/CD19- by using FCM, re-gating of cells with dim or negative CD45 expression is necessary to exclude NK cells.

In all MM cases, a single antigen cannot be used to distinguish neoplastic plasma cells. Although CD138 is expressed at high levels on plasma cells [17], this marker cannot be used to discriminate neoplastic myeloma cells from reactive plasma cells. CD56 is expressed mainly on neoplastic plasma cells although not in all cases [18]. Similarly, both CD45- and CD45+ neoplastic plasma cell populations have been described [19]. Reactive plasma cells express CD19; however, neoplastic plasma cells show no or only a dim CD19 expression [3, 6]. Mahmoud et al. [7] demonstrated that enforced expression of CD19 in human myeloma cell lines resulted in growth inhibition and reduced tumorigenicity. In our study, CD19 was not expressed in neoplastic plasma cells in any of the MM cases, regardless of the type of treatment. Because the number of patients enrolled limits our study, we cannot not exclude the possibility that some rare cases of MM may show positivity for CD19. However, in terms of our results, we conclude that the loss of CD19 expression in MM represents neoplastic myeloma cells, and that CD19 is the most useful marker to discriminate neoplastic plasma cells from reactive plasma cells. In addition, no significant difference was noted in the immunophenotypic profiles of neoplastic plasma cells between untreated and treated patients.
The role of CD45 in the biology of MM remains controversial, with variable expression patterns reported among the plasma cells in the BM of patients with MM [20]. Monoclonal gammopathy of undetermined significance (MGUS) shows equal distribution of CD45+ and CD45- plasma cells [19]. However, the percentage of plasma cells expressing CD45 in patients with new or relapsed MM, is lower than that seen in patients with MGUS or smoldering myeloma (22\% vs. $43 \%$ ) [19]. In our study, most neoplastic plasma cells had CD56- or + and CD19- expression patterns, whereas the intensity of CD45 expression varied from negative to bright. To date, no definite conclusions can be drawn regarding CD45 expression in MM patients, although most reports agree that the CD45- phenotype represents the neoplastic plasma cell population in MM [21]. Because of the varied expression patterns of CD45 on neoplastic plasma cells, there was some limitation in identifying them using CD45 alone, unlike the case with CD56 and CD19. However, the presence of CD45- neoplastic plasma cells has been associated with a poor clinical outcome [19]. Because CD45 expression may be helpful in the analysis of FCM immunophenotyping of plasma cells, we thought it important that this marker be included in our simplified FCM panel for MM.

Cytoplasmic immunoglobulin light chain restriction results from clonal proliferation of neoplastic plasma cells. FCM measurement of cytoplasmic immunoglobulin light chain can demonstrate light chain restriction patterns and can be used for supporting the diagnosis of MM [22]. However, FCM methods for the detection of cytoplasmic immunoglobulin light chain is somewhat labor-intensive and not reproducible [23, 24], and several alternative methods are available for measuring cytoplasmic light chain, including immunohistochemical staining, immunofixation electrophoresis, and serum free light chain assay. Thus, in our study, we did not use FCM to analyze cytoplasmic immunoglobulin light chain, and instead performed immunohistochemical staining of BM biopsy specimens for kappa and lambda light chains (data not shown) to further support the identification of neoplastic plasma cells.

In conclusion, the simplified FCM immunophenotyping panel, CD56/CD19/CD138(CD38)/CD45, is useful for distinguishing neoplastic myeloma cells from reactive plasma cells at the time of diagnosis and during follow-up of MM patients. In addition, CD19 represents the most valuable antigen to identify neoplastic myeloma cells in patients with MM.

\section{REFERENCES}

1. Lin P. Plasma cell myeloma. Hematol Oncol Clin North Am 2009;23:709-27.

2. Dimopoulos M, Kyle R, Fermand JP, et al. Consensus recommendations for standard investigative workup: report of the International Myeloma Workshop Consensus Panel 3. Blood 2011;117: 4701-5.

3. Harada H, Kawano MM, Huang N, et al. Phenotypic difference of 
normal plasma cells from mature myeloma cells. Blood 1993;81: 2658-63.

4. Van Camp B, Durie BG, Spier C, et al. Plasma cells in multiple myeloma express a natural killer cell-associated antigen: CD56 (NKH-1; Leu-19). Blood 1990;76:377-82.

5. Wijdenes J, Vooijs WC, Clément C, et al. A plasmocyte selective monoclonal antibody (B-B4) recognizes syndecan-1. Br J Haematol 1996;94:318-23.

6. Ocqueteau M, Orfao A, Almeida J, et al. Immunophenotypic characterization of plasma cells from monoclonal gammopathy of undetermined significance patients. Implications for the differential diagnosis between MGUS and multiple myeloma. Am J Pathol 1998;152:1655-65.

7. Mahmoud MS, Fujii R, Ishikawa H, Kawano MM. Enforced CD19 expression leads to growth inhibition and reduced tumorigenicity. Blood 1999;94:3551-8.

8. Guikema JE, Hovenga S, Vellenga E, et al. CD27 is heterogeneously expressed in multiple myeloma: low CD27 expression in patients with high-risk disease. Br J Haematol 2003;121:36-43.

9. Robillard N, Avet-Loiseau H, Garand R, et al. CD20 is associated with a small mature plasma cell morphology and $t(11 ; 14)$ in multiple myeloma. Blood 2003;102:1070-1.

10. Kovarova L, Buresova I, Buchler T, et al. Phenotype of plasma cells in multiple myeloma and monoclonal gammopathy of undetermined significance. Neoplasma 2009;56:526-32.

11. Sezer O, Heider U, Zavrski I, Possinger K. Differentiation of monoclonal gammopathy of undetermined significance and multiple myeloma using flow cytometric characteristics of plasma cells. Haematologica 2001;86:837-43.

12. Rawstron AC, Orfao A, Beksac M, et al. Report of the European Myeloma Network on multiparametric flow cytometry in multiple myeloma and related disorders. Haematologica 2008;93: 431-8.

13. Jaffe ES, Harris NL, Stein H, Vardiman JW, eds. WHO Health Organization classification of tumours. Pathology and genetics of tumours of haematopoietic and lymphoid tissues. Volume 3. Lyon, France: IARC Press, 2001.

14. Sandoval-Montes C, Santos-Argumedo L. CD38 is expressed selectively during the activation of a subset of mature T cells with reduced proliferation but improved potential to produce cytokines. J Leukoc Biol 2005;77:513-21.

15. Lin P, Owens R, Tricot G, Wilson CS. Flow cytometric immunophenotypic analysis of 306 cases of multiple myeloma. Am J Clin Pathol 2004;121:482-8.

16. Reid S, Yang S, Brown R, et al. Characterisation and relevance of CD138-negative plasma cells in plasma cell myeloma. Int J Lab Hematol 2010;32:e190-6.

17. Rawstron AC. Immunophenotyping of plasma cells. Curr Protoc Cytom 2006; Chapter 6:Unit6.23.

18. Sahara N, Takeshita A, Shigeno K, et al. Clinicopathological and prognostic characteristics of CD56-negative multiple myeloma. Br J Haematol 2002;117:882-5.

19. Kumar S, Rajkumar SV, Kimlinger T, Greipp PR, Witzig TE. CD45 expression by bone marrow plasma cells in multiple myeloma: clinical and biological correlations. Leukemia 2005;19:1466-70.

20. Pellat-Deceunynck C, Bataille R. Normal and malignant human plasma cells: proliferation, differentiation, and expansions in relation to CD45 expression. Blood Cells Mol Dis 2004;32:293301.

21. Raja KR, Kovarova L, Hajek R. Review of phenotypic markers used in flow cytometric analysis of MGUS and MM, and applicability of flow cytometry in other plasma cell disorders. Br J Haematol 2010;149:334-51.

22. Chang CC, Schur BC, Kampalath B, Lindholm P, Becker CG, Vesole DH. A novel multiparametric approach for analysis of cytoplasmic immunoglobulin light chains by flow cytometry. Mod Pathol 2001;14:1015-21.

23. Barlogie B, Alexanian R, Pershouse M, Smallwood L, Smith L. Cytoplasmic immunoglobulin content in multiple myeloma. J Clin Invest 1985;76:765-9.

24. Slaper-Cortenbach IC, Admiraal LG, Kerr JM, van Leeuwen EF, von dem Borne AE, Tetteroo PA. Flow-cytometric detection of terminal deoxynucleotidyl transferase and other intracellular antigens in combination with membrane antigens in acute lymphatic leukemias. Blood 1988;72:1639-44. 